KING'S COLLEGE HOSPITAL.

\author{
C A S E S \\ AND \\ CLI N I CA L O BSER VATIONS \\ $\mathrm{BY}$
}

MR. FERGUSSON.

LOOSE CARTILAGES IN THECA OF WRIST,

Mary Ann Johnston, ratat. 23, was admitted December 27, 1842. Two years ago without any apparent cause, was attacked with sudden and severe pain on the back of the hand, and about a week after perceived a slight sweiling a little below the wrist, which gradually increased so as to become quite conspicuous both above and below the joint. Attempts have been made to burst the tumour, and various means have been tried in vain to cause its dispersion. At present there is an oval-shaped swelling extending between two and three inches in the course of the extensor tendons. Fluctuation can be felt at any part, but is most distinct below and above the annular ligament. The extensor tendons cannot be perceived beneath the skin She has now little or no pain in the part; the movements of the wrist-joint are executed with facility, but the swelling is such as to induce her to submit to any means that may be proposed for its removal.

31. An attempt having been made to burst the tumour, which proved ineffectual, a small incision was made below the annular ligament, through which a glairy fluid escaped, and also about thirty fibro-cartilaginous bodies, varying in size from a pickle of boiled rice to that of a field-bean. Force was required to squeeze out some of these bodies, the opening having been purposely very limited. Latterly, some ragged shreds of lymph escaped, and when the sac (which could now be distinctly felt) seemed emptied, the wound was accurately closed, and a splint haying been laid on the anterior aspect of the limb, a bandage was applied to pre. vent the movements of the wrist, and at the same time to keep up moderate pressure on the contracted cyst. The parts to be fomented should any pain come on; the patient to keep her bed, and the hand and forearm to be supported on a pillow.

Jan. 7, 1843. Considerable cedema in the vicinity of the sac, but no appearance of its refilling; has suffered little constitutional irritation since the operation.

9. Complains of pain over the wrist; bandage and splint removed ; surface slightly inflamed; poultice to be applied, and the arm still to be kept on the pillow as before.

11. A small quantity of pus has escaped from the wound; the oedema and other symptoms of inflammation bave considerably abated.
Since the last report nothing particular has occurred, excepting on one occasion a slight accession of inflammation, which subsided on the discharge of a little pus from the wound. In the course of a fortnight the patient left the house with the wound closed, and the swelling greatly diminished. She has since presented herself on several occasions, the swelling having almost entirely left; complains of no pain, and can move the wrist as readily as before she came under treatment. Has during her absence made use of iodine ointment over the indurated parts.

It was stated by Mr. Fergusson that as the tumour showed every disposition to increase, he had deemed it best at once to adopt the practice which had been pursued in this case, as such would have become absolutely necessary at some subsequent period when the danger wonld have been considerably greater. Surgeons were never very anxious to open into such tumours, $2 \mathrm{~s}$ the inflammation which was likely to be thereby induced often gave rise to very serious results. This case had differed from those usually met with in a similar situation; the presence of these loose bodies being by no means common, more especially of such a large size. The thickness of the sac had prevented these bodies being felt, and he was somewhat amazed when they followed each other through the opening. Considerdering their presence, and that they must always have kept up irritation within, he doubted if any other practice could have been so efficient as that adopted, and although originally he had made the opening only with the view of permitting the escape of a gelatinous kind of fluid, which he sup. posed to be present, he had at once reason to be pleased with the proceeding, as these objects could have been got rid of in no other way.

The pupils must have observed how very careful he had been in the after-treatment to adopt such local and constitutional means as were most likely to avert injurious inflammation. The slight suppuration which had occurred had been productive of no great harm, whilst possibly the inflam. matory action in the vicinity had caused the complete obliteration of the sac.

\section{YUNGUS HæMATODES.}

Thomas Hendly, ætat. 36, labourer, admitted 20th January, 1843. Five years ago first perceived a small tumour about the size of a pea, under the skin on the left thigh, a little below Poupart's ligament. It was slightly painful at first, but not so latterly, except after much walking. Had experienced no violence on the part, and could give no cause for the origin of the growth, which continued gradually and slowly to increase without causing him much alarm 
until within the last fortnight, during which period it has added nearly a third to its bulk, which is now that of a child's head. The skin on the tumour had continued of the same colour as that on the rest of the body, until the 16th inst. (four days ago), when a dark spot appeared, and speedily spread over several inches of the surface, the swelling during this period continuing to enlarge with increased rapidity. Has been much jaundiced for the last eight days, but has never had this complaint before. Has latterly been subject to epistaxis, and a week ago the bleeding continued for eight hours; bowels confined ; tongue foul ; much thirst; pulse full and slow. To-day a crack has formed on the blackened skin, and a small dark-coloured fungus has presented, from which there is an occasional escape of blood. To have a calomel purge, and warm-water dressings over the affected part.

22. Since last report sloughing has extended, and a black fungous mass has shot above the level of the surrounding skin. The bleeding from the open surface has been copious. Alum lotion has been applied with good effect, and two grains of acetate of lead, with half a grain of opium, have been given every four hours.

23. Bleeding has been less alarming; jaundice somewhat abated; has passed a restless night; slough of the skin has separated, and the fungus has become more apparent. The fetor is great, and a lotion of chloride of lime has been ordered.

25. Several large pieces of the fungus have dropped off; no bleeding. Patient to have four ounces of wine daily.

28. Fungus not half its original size; portions of it separate daily.

Feb. 5. Since last report jaundice has almost disappeared; the tumour has continued to diminish, but considerable nedema in the thigh has supervened. Patient has gradually become weaker, and sank from exhaustion this morning at four o'clock.

Sectio Cadaveris, Thirty Hours after Death.

Head not examined. Contents of thorax quite healthy; abdominal viscera in a similar condition, with the exception, perhaps, of the pancreas, which was somewhat larger than usual. The gall-bladder was distended with bile, and the cystic duct was slightly contracted. The prominent part of the tumour had almost entirely sloughed away; its base was incorporated with all the surrounding parts, encircling the femoral vessels and nerves, and extending upwards into the iliac fossa. The disease seemed to have been originally superficial to the fascia lata (probably in a lymphatic gland), but had latterly involved that membrane and all the contiguous tissues, which seemed infiltrated with a yellowish-coloured lymph. No other part of the body presented any trace of disease.
Mr. Fergusson observed that this case was one of a rare character, for although the term fungus hæmatodes was frequently in use, the true bleeding fungus was comparatively seldom met with. Most soft tumours of a malignant character, which were not called cancerous, were designated fungus hæmatodes, but perhaps the term medullary disease was more appropriate. Here, however, had been an example of a bleeding fungus which had exhibited most of the usual features of this remarkable affection. At first, in all pro. bability, the swelling had been of a medul. lary character, and had progressed but slowly, but within three weeks of the person's death an altered action had caused those stages with which the pupils had become familiar. Had the tumour been seen at an early date, possibly its removal might have saved life, but such a proceeding could not have been justifiable at any period after the last fatal excitement had commenced. Since the patient had entered the hospital no idea of an operation could be entertained, for even before the dissection was made it had been quite apparent that the neighbouring textures were so involved as to preclude any attempts of the kind. During the first few days he had imagined that the jaundice had been produced by the pressure of some internal tumour on the large gall-ducts, but as the disease seemed to yield under the influence of medicines he had been uncertain on this point. Considering the frequency with which the internal organs are affected in cases of this description, it was not unreasonable to suppose that the natural course of the bile was obstructed by some medullary growth in the abdomen. He firmly ex. pected to see such tumours in both chest and abdomen, and had been surprised at their absence. This latter circumstance confirmed the opinion that had the disease been removed at any period before the neighbouring tissues became involved, the operation might have been followed with perfect success.

REDUCTION OF FEMORAL H E R N I A

$O N$

\section{DR. O'BEIRNE'S PLAN.}

\section{To the Editor of THE LANCET.}

Srr,-I send the following case for insel" tion in your Journal. The patient was a most unfavourable subject for an operation, and was relieved by a plan of treatment which I understand bas been very success. fully adopted in Ireland, and which I hope in many cases may prevent the necessity of having recourse to a painful and dangerous operation :--

Mrs. Russell, ætat. 51, very corpulent, ruptured herself on the right side twenty. four years since, in lifting a heavy weight, and, until within a fortnight, has not worn a 